Regular Article

\title{
Functional balance between enzymes in malonyl-CoA pathway for 3-hydroxypropionate biosynthesis
}

\author{
Changshui Liu ${ }^{\mathrm{a}, \mathrm{b}}$, Yamei Ding ${ }^{\mathrm{c}}$, Rubing Zhang ${ }^{\mathrm{a}}$, Huizhou Liu ${ }^{\mathrm{a}}$, Mo Xian ${ }^{\mathrm{a}, *}$, Guang Zhao ${ }^{\mathrm{a}, *}$ \\ ${ }^{a}$ CAS Key Lab of Biobased Materials, Qingdao Institute of Bioenergy and Bioprocess Technology, Chinese Academy of Sciences, Qingdao 266101, China \\ ${ }^{\mathrm{b}}$ University of Chinese Academy of Sciences, Beijing 100049, China \\ ${ }^{\mathrm{c}}$ Institute of Oceanology, Chinese Academy of Sciences, Qingdao 266071, China
}

\section{A R T I C L E I N F O}

\section{Article history:}

Received 7 September 2015

Received in revised form

30 October 2015

Accepted 4 January 2016

Available online 11 January 2016

Keywords:

3-hydroxypropionate

Malonyl-CoA pathway

Malonyl-CoA reductase

Enzymatic activity imbalance

Recombinant E. coli

\begin{abstract}
A B S T R A C T
3-Hydroxypropionate (3HP) is an important platform chemical, and four 3HP biosynthetic routes were reported, in which the malonyl-CoA pathway has some expected advantages but presented the lowest $3 \mathrm{HP}$ yield. Here, we demonstrated that this low yield was caused by a serious functional imbalance between MCR-C and MCR-N proteins, responsible for the two-step reduction of malonyl-CoA to 3HP. Then we minimized the enzyme activity imbalance by directed evolution of rate-limiting enzyme MCR-C and fine tuning of MCR-N expression level. Combined with culture conditions optimization, our engineering approaches increased the 3HP titer 270 -fold, from $0.15 \mathrm{~g} / \mathrm{L}$ to $40.6 \mathrm{~g} / \mathrm{L}$, representing the highest 3HP production via malonyl-CoA pathway so far. This study not only significantly improved the $3 \mathrm{HP}$ productivity of recombinant Escherichia coli strain, but also proved the importance of metabolic balance in a multistep biosynthetic pathway, which should be always considered in any metabolic engineering study.
\end{abstract}

๑ 2016 International Metabolic Engineering Society. Published by Elsevier Inc. All rights reserved.

\section{Introduction}

3-Hydroxypropionate (3HP) is an important platform chemical, ranked in the list of top 12 value added chemicals from biomass by US Department of Energy (Werpy and Petersen, 2004). There are several 3HP biosynthetic pathways reported, and 3HP can be produced from at least four intermediates: glycerol (Raj et al., 2008), lactate (Henry et al., 2010), $\beta$-alanine (Borodina et al., 2014), and malonyl-CoA (Rathnasingh et al., 2012). Among all these routes, malonyl-CoA pathway has some expected advantages, such as broad raw material spectrum, thermodynamical feasibility, redox netural, and cofactors independence, and was reconstructed in Escherichia coli (Liu et al., 2013; Rathnasingh et al., 2012), Saccharomyces cerevisiae (Chen et al., 2014) and Synechococcus elongatus (Lan et al., 2015). However, all recombinant strains carrying malonyl-CoA pathway presented low 3HP yield. The highest 3HP production via malonyl-CoA pathway was $659 \mathrm{mg} / \mathrm{L}$, achieved in recombinant $S$. elongatus strain after 16 days of cultivation (Lan et al., 2015).

The malonyl-CoA reductase (MCR) of Chloroflexus aurantiacus catalyzes a two-step NADPH-dependent reduction of malonyl-CoA

\footnotetext{
* Corresponding authors. Fax: + 8653280662765.

E-mail addresses: xianmo@qibebt.ac.cn (M. Xian), zhaoguang@qibebt.ac.cn (G. Zhao).
}

to 3HP (Hugler et al., 2002). In our previous study, this enzyme was dissected into two functionally distinct fragments (Liu et al., 2013). The malonyl-CoA was reduced into intermediate malonate semialdehyde (MSA) by MCR-C fragment (amino acids 550-1219), and further reduced to 3HP by MCR-N fragment (amino acids 1549). The overall enzyme activity increased when MCR was separated into two individual fragments. A 3HP-producing strain Q1319 was constructed by introducing plasmids pA-accADBC carrying acetyl-CoA carboxylase genes of $E$. coli and pMCR-N-C encoding that separated MCR fragments into E. coli BL21(DE3) (Fig. 1 and Table 1). Under shaking flask conditions, this strain produced $0.15 \mathrm{~g} / \mathrm{L} 3 \mathrm{HP}, 1.5$ times higher than that of control strain carrying the full-length $\mathrm{mor}$ gene (Liu et al., 2013).

In strain Q1319, it was found that MCR-N protein level in crude cell extract was significantly higher than MCR-C fragment even though both genes were codon-optimized and controlled by the same T7 promoter (Liu et al., 2013). Taken into account that the initial reduction of malonyl-CoA catalyzed by MCR-C was ratelimiting step (Hugler et al., 2002; Liu et al., 2013), there must be a serious imbalance between activities of these two enzymes. However, previous studies have proved that the balance of enzyme activities is essential in a multistep pathway, and adjusting the protein expression level to improve production is not simply in a manner of "the more the better". For instance, in an in vitro reaction to synthesize fatty acid, increasing amounts of FabF, FabH, or TesA enhance fatty acid synthases activity at low concentrations, but 


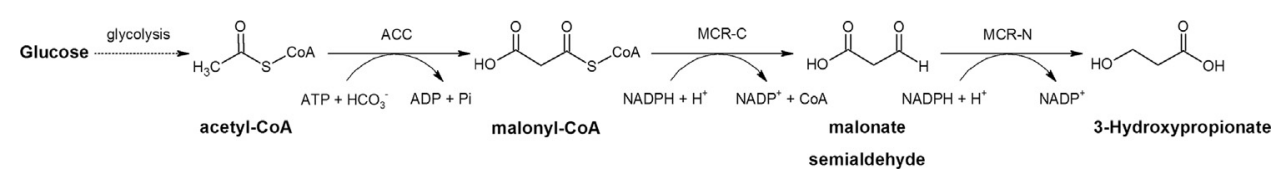

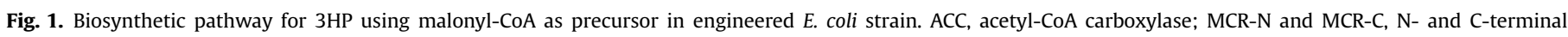
fragments of malonyl-CoA reductase.

Table 1

Bacteria strains and plasmids used in this study.

\begin{tabular}{|c|c|c|}
\hline Strains and plasmids & Description & Source \\
\hline \multicolumn{3}{|l|}{ Strains } \\
\hline E. coli $\mathrm{DH} 5 \alpha$ & $\mathrm{F}^{-}$supE44 $\Delta$ lacU169 ( $\phi 80$ lacZ $\left.\Delta M 15\right)$ hsdR17 recA1 endA1 gyrA96 thi-1 relA1 & Invitrogen \\
\hline E. coli BL21(DE3) & $\mathrm{F}^{-}$ompT gal dcm lon hsdSB $\left(\mathrm{rB}^{-} \mathrm{mB}^{-}\right) \lambda(\mathrm{DE} 3)$ & Invitrogen \\
\hline E. coli $\chi 7213$ & thi-1 thr-1 leuB6 glnV44 fhuA21 lacY1 recA1 RP4-2-Tc:Mu $\lambda$ pir $\Delta a s d A 4 \Delta z h f-2: \operatorname{Tn} 10$ & (Roland et al., 1999) \\
\hline Q1319 & E. coli BL21(DE3)/pA-accADBC/pMCR-N-C & (Liu et al., 2013) \\
\hline Q1491 & E. coli BL21(DE3) $\Delta$ panD & This study \\
\hline Q2015 & E. coli $\mathrm{BL} 21(\mathrm{DE} 3) \Delta p r p R:$ lacI $\mathrm{P}_{\mathrm{T} 7} \mathrm{His}_{6}-$ mcr $_{1-549}$ & This study \\
\hline Q2021 & Q2015/pA-accADBC/pMCR-C N940V/K1106W/S1114R & This study \\
\hline Q2204 & E. coli BL21(DE3)/pA-accADBC/pMCR-N-C N940V/K1106W/S1114R & This study \\
\hline Q2095 & E. coli BL21(DE3) $\Delta$ prpR:lacl $\mathrm{P}_{\mathrm{T} 7} \mathrm{His}_{6}-\mathrm{mcr}_{1-549} \Delta$ melR:lacl $\mathrm{P}_{\mathrm{T} 7} \mathrm{His}_{6}-\mathrm{mcr}_{1-549}$ & This study \\
\hline Q2098 & E. coli BL21(DE3) $\Delta$ prpR:lacI $\mathrm{P}_{\mathrm{T} 7}$ His $_{6}-$ mcr $_{1-549} \Delta$ melR:lacI $\mathrm{P}_{\mathrm{T} 7}$ His $_{6}-$ mcr $_{1-549} \Delta m$ tlA:lacI $\mathrm{P}_{\mathrm{T} 7}$ His $_{6}-$ mcr $_{1-549}$ & This study \\
\hline Q2185 & Q2095/pA-accADBC/pMCR-C N940V/K1106W/S1114R & \\
\hline Q2186 & Q2098/pA-accADBC/pMCR-C N940V/K1106W/S1114R & This study \\
\hline \multicolumn{3}{|l|}{ Recombinant plasmids } \\
\hline pACYCDuet-1 & rep $_{\mathrm{p} 15 \mathrm{~A}} \mathrm{Cm}^{\mathrm{R}}$ lacI $\mathrm{P}_{\mathrm{T} 7}$ & Novagen \\
\hline pETDuet-1 & rep $_{\mathrm{pBR} 322} \mathrm{Amp}^{\mathrm{R}}$ lacI $\mathrm{P}_{\mathrm{T} 7}$ & Novagen \\
\hline $\mathrm{pA}-a c c A D B C$ & $\operatorname{rep}_{\mathrm{p} 15 \mathrm{~A}} C^{\mathrm{R}}$ lacI $\mathrm{P}_{\mathrm{T} 7}$ accA $\mathrm{P}_{\mathrm{T} 7}$ accD $\mathrm{P}_{\mathrm{T} 7} a c c B C$ & (Cao et al., 2011) \\
\hline pMCR & rep $_{\mathrm{pBR} 322} \mathrm{Amp}^{\mathrm{R}}$ lacI $\mathrm{P}_{\mathrm{T} 7} \mathrm{His}_{6}-\mathrm{mcr}$ & (Liu et al., 2013) \\
\hline pMCR-N & rep $_{\mathrm{pBR} 322} \mathrm{Amp}^{\mathrm{R}}$ lacI $\mathrm{P}_{\mathrm{T} 7} \mathrm{His}_{6}-\mathrm{mcr}_{1-549}$ & (Liu et al., 2013) \\
\hline pMCR-C & rep $_{\mathrm{pBR} 322} \mathrm{Amp}^{\mathrm{R}}$ lacI $\mathrm{P}_{\mathrm{T} 7} \mathrm{His}_{6}-\mathrm{mcr}_{550-1219}$ & (Liu et al., 2013) \\
\hline pMCR-N-C & rep $_{\mathrm{pBR} 322}$ Amp $^{\mathrm{R}}$ lacI $\mathrm{P}_{\mathrm{T} 7}$ His $_{6}-$ mcr $_{1-549} \mathrm{P}_{\mathrm{T} 7}$ His $_{6}-$ mcr $_{550-1219}$ & (Liu et al., 2013) \\
\hline pBAPAT & rep $_{\mathrm{pBR} 322} \mathrm{Amp}^{\mathrm{R}}$ lacl $\mathrm{P}_{\mathrm{T} 7}$ PP_0596 & (Wang et al., 2014) \\
\hline PA-MCR-N & rep $_{\mathrm{p} 15 \mathrm{~A}} \mathrm{Cm}^{\mathrm{R}}$ lacI $\mathrm{P}_{\mathrm{T} 7} \mathrm{His}_{6}-$ mcr $_{1-549}$ & This study \\
\hline pBAPAT-MCR-C & rep $_{\mathrm{pBR} 322} \mathrm{Amp}^{\mathrm{R}}$ lacI $\mathrm{P}_{\mathrm{T} 7} \mathrm{His}_{6}-$ mcr $_{550-1219} \mathrm{P}_{\mathrm{T} 7}$ PP_0596 & This study \\
\hline pMCR-C-L818P & rep $_{\mathrm{pBR} 322} \mathrm{Amp}^{\mathrm{R}}$ lacI $\mathrm{P}_{\mathrm{T} 7} \mathrm{His}_{6}-$ mcr $_{550-1219} \mathrm{~L} 818 \mathrm{P}$ & This study \\
\hline pMCR-C-N940S & rep $_{\mathrm{pBR} 322} \mathrm{Amp}^{\mathrm{R}}$ lacI $\mathrm{P}_{\mathrm{T} 7} \mathrm{His}_{6}-$ mcr $_{550-1219}$ N940S & This study \\
\hline pMCR-C-A763T & rep $_{\mathrm{pBR} 322} \mathrm{Amp}^{\mathrm{R}}$ lacI $\mathrm{P}_{\mathrm{T} 7} \mathrm{His}_{6}-$ mcr $_{550-1219}$ A763T & This study \\
\hline pMCR-C-T979A & rep $_{\mathrm{pBR} 322} \mathrm{Amp}^{\mathrm{R}}$ lacI $\mathrm{P}_{\mathrm{T} 7} \mathrm{His}_{6}-\mathrm{mcr}_{550-1219} \mathrm{~T} 979 \mathrm{~A}$ & This study \\
\hline pMCR-C-S1114R & rep $_{\mathrm{pBR} 322} \mathrm{Amp}^{\mathrm{R}}$ lacI $\mathrm{P}_{\mathrm{T} 7} \mathrm{His}_{6}-\mathrm{mcr}_{550-1219} \mathrm{~S} 1114 \mathrm{R}$ & This study \\
\hline pMCR-C-K1106R & rep $_{\mathrm{pBR} 322} \mathrm{Amp}^{\mathrm{R}}$ lacI $\mathrm{P}_{\mathrm{T} 7} \mathrm{His}_{6}-\mathrm{mcr}_{550-1219} \mathrm{~K} 1106 \mathrm{R}$ & This study \\
\hline pMCR-C-V739A & rep $_{\mathrm{pBR} 322} \mathrm{Amp}^{\mathrm{R}}$ lacI $\mathrm{P}_{\mathrm{T} 7} \mathrm{His}_{6}-\mathrm{mcr}_{550-1219} \mathrm{~V} 739 \mathrm{~A}$ & This study \\
\hline pMCR-C-L843Q & rep $_{\mathrm{pBR} 322} \mathrm{Amp}^{\mathrm{R}}$ lacI $\mathrm{P}_{\mathrm{T} 7} \mathrm{His}_{6}-\mathrm{mcr}_{550-1219} \mathrm{~L} 843 \mathrm{Q}$ & This study \\
\hline pMCR-C-N940V & rep $_{\mathrm{pBR} 322} \mathrm{Amp}^{\mathrm{R}}$ lacI $\mathrm{P}_{\mathrm{T} 7} \mathrm{His}_{6}-\mathrm{mcr}_{550-1219} \mathrm{~N} 940 \mathrm{~V}$ & This study \\
\hline pMCR-C-K1106W & rep $_{\mathrm{pBR} 322} \mathrm{Amp}^{\mathrm{R}}$ lacI $\mathrm{P}_{\mathrm{T} 7} \mathrm{His}_{6}-\mathrm{mcr}_{550-1219} \mathrm{~K} 1106 \mathrm{~W}$ & This study \\
\hline pMCR-C-N940V/K1106W & rep $_{\mathrm{pBR} 322} \mathrm{Amp}^{\mathrm{R}}$ lacI $\mathrm{P}_{\mathrm{T} 7} \mathrm{His}_{6}-\mathrm{mcr}_{550-1219}$ N940V K1106W & This study \\
\hline pMCR-C-N940V/S1114R & rep $_{\mathrm{pBR} 322} \mathrm{Amp}^{\mathrm{R}}$ lacI $\mathrm{P}_{\mathrm{T} 7} \mathrm{His}_{6}-\mathrm{mcr}_{550-1219}$ N940V S1114R & This study \\
\hline pMCR-C-K1106W/S1114R & rep $_{\mathrm{pBR} 322} \mathrm{Amp}^{\mathrm{R}}$ lacI $\mathrm{P}_{\mathrm{T} 7} \mathrm{His}_{6}-\mathrm{mcr}_{550-1219} \mathrm{~K} 1106 \mathrm{~W}$ S1114R & This study \\
\hline pMCR-C-N940V/K1106W/S1114R & rep $_{\mathrm{pBR} 322} \mathrm{Amp}^{\mathrm{R}}$ lacI $\mathrm{P}_{\mathrm{T} 7} \mathrm{His}_{6}-\mathrm{mcr}_{550-1219}$ N940V K1106W S1114R & This study \\
\hline pMCR-N-C-N940V/K1106W/S1114R & rep $_{\mathrm{pBR} 322}$ Amp $^{\mathrm{R}}$ lacI $\mathrm{P}_{\mathrm{T} 7}$ His $_{6}-$ mcr $_{1-549} \mathrm{P}_{\mathrm{T} 7}$ His $_{6}-$ mcr $_{550-1219}$ N940V K1106W S1114R & This study \\
\hline \multicolumn{3}{|l|}{ Suicide plasmids } \\
\hline pRE112 & oriT oriV sacB cat & (Edwards et al., 1998) \\
\hline pRE112- $\Delta$ prpR & oriT oriV sacB cat $\Delta$ prpR & (Gao et al., 2014) \\
\hline pLC02 & oriT oriV sacB cat $\Delta$ prpR:lacI $\mathrm{P}_{\mathrm{T} 7}$ His $_{6}-$ mcr $_{1-549}$ & This study \\
\hline pLC03 & oriT oriV sacB cat $\Delta$ panD & This study \\
\hline pLC04 & oriT oriV sacB cat $\Delta$ melR:lacI $\mathrm{P}_{\mathrm{T} 7} \mathrm{His}_{6}-$ mcr $_{1-549}$ & This study \\
\hline pLC05 & oriT oriV sacB cat $\Delta m$ tlA:lacI $\mathrm{P}_{\mathrm{T} 7}$ His $_{6}-m_{1-549}$ & This study \\
\hline
\end{tabular}

repress fatty acid production at higher concentrations (Yu et al., 2011). In addition, the pentadecaheptaene production of recombinant E. coli strain is strongly dependent on the ratio of two key enzymes, SgcE10 and SgcE. The optimal SgcE10:SgcE ratio is 8, and a lower or higher ratio both negatively affected pentadecaheptaene production (Liu et al., 2015). Therefore, we presume that the imbalance between MCR-N and MCR-C is attributing to the low production of 3HP. Furthermore, the excessive expression of MCR-N protein may also cause protein misfolding or metabolic burden in host strain.

Therefore, this study aims to further develop and improve the 3HP productivity of the recombinant strain. The activity imbalance between MCR-N and MCR-C was minimized using two strategies: (1) the enzymatic activity of MCR-C fragment was improved by directed evolution; (2) the expression level of MCR-N was decreased by chromosomal integration of $m c r-n$ gene. Finally, our resultant strain accumulated $3.72 \mathrm{~g} / \mathrm{L}$ and $40.6 \mathrm{~g} / \mathrm{L} 3 \mathrm{HP}$ using glucose as sole carbon source in shaking flask cultivation and fedbatch fermentation, respectively, representing the highest 3HP production via malonyl-CoA pathway so far.

\section{Materials and methods}

\subsection{Bacterial strains and growth conditions}

All strains and plasmids used in this study are listed in Table 1. All primers used in this study are listed in Table 2. E. coli DH5 $\alpha$ 
Table 2

Primers used in this study.

\begin{tabular}{|c|c|}
\hline Primer No & Sequence \\
\hline \multicolumn{2}{|c|}{$\Delta p a n D$ construction } \\
\hline 414 & CAGAGCTCACTGAGCATGGTGCAGCTGG \\
\hline 415 & AAAGCGATTCCGGTACAGGTTGC \\
\hline 416 & GCAACCTGTACCGGAATCGCTTTGCCCTGCAGCATCGTGCGAATC \\
\hline 417 & ATCTGCGGTACCTCGTGGTCAGCCTCCAGATGC \\
\hline \multicolumn{2}{|c|}{$m c r-n$ cloning in $\mathrm{pA}-\mathrm{MCR}-\mathrm{N}$} \\
\hline 233 & CATGGATCCGAGCGGAACAGGACGAC \\
\hline 834 & ACGTGGTACCTTAAATGTTGGCAGGGATGTTGAG \\
\hline \multicolumn{2}{|c|}{$\Delta$ melR:lacl $\mathrm{P}_{\mathrm{T} 7} m c r_{1-549}$ construction } \\
\hline 532 & CAGAGCTCATGCGCCAGTATGGTCAAG \\
\hline 925 & GTACCGGTACCGATCGTTCTAGAGCAAACTTAGCCAACAGCGC \\
\hline 926 & TCTAGAACGATCGGTACCGGTACGATCAGGTATTCCACATCGC \\
\hline 535 & ATCTGCGCTAGCACAGATGCGGAATGGTACGTAG \\
\hline \multicolumn{2}{|c|}{$\Delta m$ tlA:lacI $\mathrm{P}_{\mathrm{T} 7} m c r_{1-549}$ construction } \\
\hline 426 & CAGAGCTC CAAATATCGGCGCGTTTATC \\
\hline 927 & GTACCGGTACCGATCGTTCTAGACGCTACCACGACCAAAGAAC \\
\hline 928 & TCTAGAACGATCGGTACCGGTACGCAGGTCTGTCGCAGATTTC \\
\hline 429 & ATCTGCGCTAGC CCAGACGCTCGATGACGG \\
\hline \multicolumn{2}{|c|}{$m c r-c$ cloning in pBAPAT-MCR-C } \\
\hline 295 & CATCAGATCTCCATCACCATCATCACCATCACAGCGCCACCACCGGCGCA \\
\hline 126 & CCCTCGAGGAATTTACACGGTAATCGC \\
\hline \multicolumn{2}{|c|}{ V739A site-directed mutagenesis } \\
\hline 634 & AGGCGGCGTAATCGGCACGGTTG \\
\hline 635 & ACCGTGCCGATTACGCCGCCTCGAAGGCTGGTCAGCG \\
\hline \multicolumn{2}{|c|}{ A763T site-directed mutagenesis } \\
\hline 602 & TGGTATTGATCTGTATCTCCGGG \\
\hline 603 & AGATACAGATCAATACCATTGCGCCGGGTCCGG \\
\hline \multicolumn{2}{|c|}{ L818P site-directed mutagenesis } \\
\hline 588 & ACCGGTTCGTGCATAGATCGC \\
\hline 589 & ATCTATGCACGAACCGGTTGAACTGCTCTTACCC \\
\hline \multicolumn{2}{|c|}{ L843P site-directed mutagenesis } \\
\hline 636 & TGCCTGTTCACGCAACGCGGTAGG \\
\hline 637 & ACCGCGTTGCGTGAACAGGCACGACGTTTTCGCAGC \\
\hline \multicolumn{2}{|c|}{ N940S site-directed mutagenesis } \\
\hline 592 & ACACTGCGGTCGGCAAGGTAATAG \\
\hline 593 & TACCTTGCCGACCGCAGTGTCAGTGGTGAGACATTC \\
\hline \multicolumn{2}{|c|}{ N940V site-directed mutagenesis } \\
\hline 800 & GCGGTCGGCAAGGTAATAG \\
\hline 801 & TATTACCTTGCCGACCGCGTGGTCAGTGGTGAGACATTCC \\
\hline \multicolumn{2}{|c|}{ T979A site-directed mutagenesis } \\
\hline 604 & ACCGCGCTTCCGACCAGCTCCGCC \\
\hline 605 & AGCTGGTCGGAAGCGCGGTCTATCTGATAGGTG \\
\hline \multicolumn{2}{|c|}{ K1106W site-directed mutagenesis } \\
\hline 798 & GCGCGCTACCCGGAAATG \\
\hline 799 & ATTTCCGGGTAGCGCGCTGGATTGCCCTGAGTGATGGTG \\
\hline \multicolumn{2}{|c|}{ S1114R site-directed mutagenesis } \\
\hline 606 & AGACGGGCACCATCACTCAGGGC \\
\hline 607 & TGAGTGATGGTGCCCGTCTCGCGCTGGTCACTC \\
\hline \multicolumn{2}{|c|}{ N940X saturation mutagenesis } \\
\hline 658 & TCGGCAAGGTAATAGACGGTG \\
\hline 664 & CCGCNNNGTCAGTGGTGAGACATTCC \\
\hline \multicolumn{2}{|c|}{ K1106X saturation mutagenesis } \\
\hline 665 & GCGCTACCCGGAAATGGTG \\
\hline 666 & GCNNNATTGCCCTGAGTGATGGTG \\
\hline \multicolumn{2}{|c|}{ S1114X saturation mutagenesis } \\
\hline 667 & AGNNNGGCACCATCACTCAGGGC \\
\hline 668 & CGCGCTGGTCACTCCCGAAAC \\
\hline
\end{tabular}

was used as the host to construct and store all recombinant plasmids, E. coli $\chi 7213$ strain was used for preparation of all suicide vectors, and E. coli BL21(DE3) strain was used for protein expression and $3 \mathrm{HP}$ production. Bacteria were grown at $37^{\circ} \mathrm{C}$ in Luria-Bertani (LB) broth unless specified. Diaminopimelic acid (DAP) $(50 \mathrm{mg} / \mathrm{ml})$ was used for the growth of $\chi 7213$ strain. In all genetic selection and 3HP production experiments, pA-accADBC was used to enhance the intracellular concentration of malonylCoA. When necessary, antibiotics were added at final concentration of $100 \mathrm{mg} / \mathrm{ml}$ for ampicillin and $50 \mathrm{mg} / \mathrm{ml}$ for chloramphenicol. LB agar containing $10 \%$ sucrose was used for sacB gene-based counter selection in allelic exchange experiments.

\subsection{Chromosomal integration of mor-n gene}

The primers used are listed in Table 2. The integration was carried out using suicide vector pRE112 as previously described (Edwards et al., 1998). The mcr-n gene was cloned from pMCR by PCR with primers 233/834, and inserted into the BamHI and $\mathrm{KpnI}$ sites of pACYCDuet-1 to generate pA-MCR-N. The plasmid pAMCR-N was digested with $\mathrm{XbaI}$ and $\mathrm{KpnI}$, and the fragment containing lacI gene, T7 promoter and mcr-n gene was inserted into the corresponding sites of pRE112- $\Delta$ prpR to generate the plasmid pLC02, which was used to mediate the allelic exchange to generate $\Delta$ prpR:lacI PT7 His $_{6}-$ mcr $_{1-549}$ strain (Q2015). The integrations of 
B
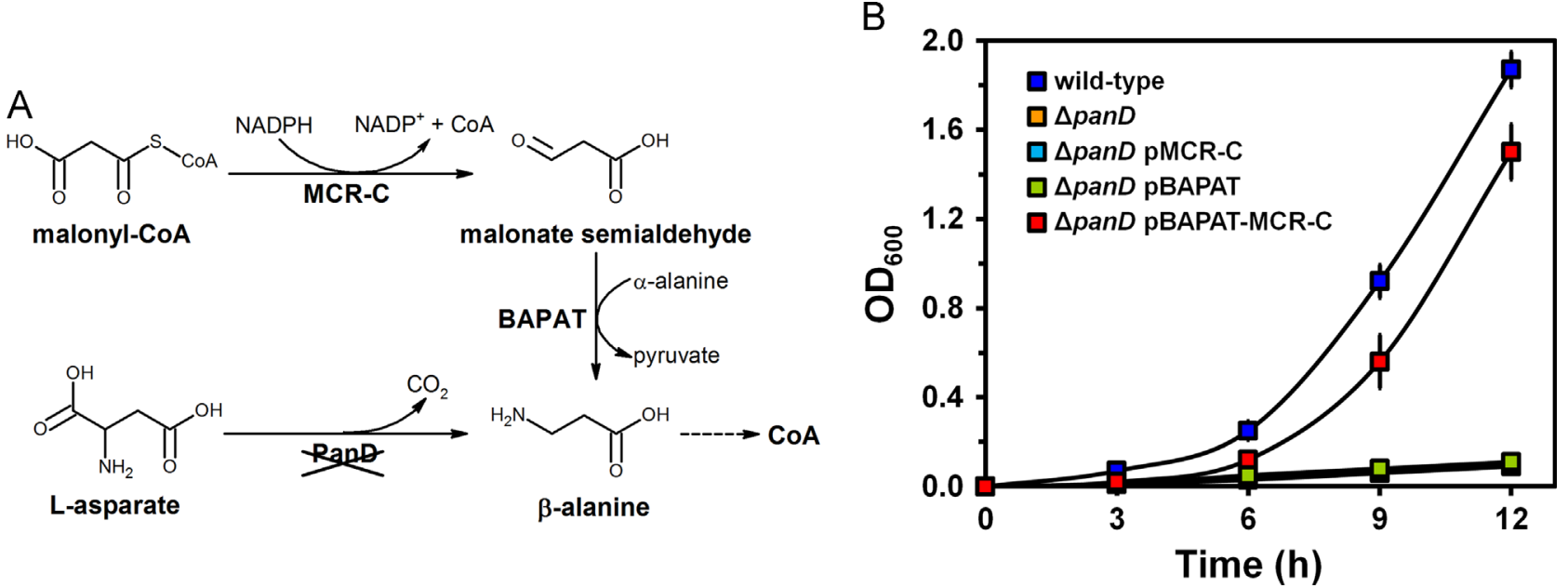

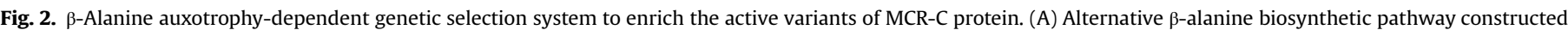

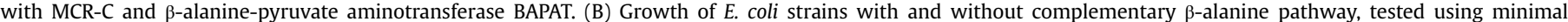
medium. The experiment was performed under shake flask condition in triplicate.

$m c r-n$ gene at the melR and $m$ tlA loci were carried out in similar way.

\subsection{Directed evolution}

For the panD deletion, two pairs of primers, 414/415 and 416/ 417, were used to amplify approximately 600-bp fragments upstream and downstream of the gene panD from BL21(DE3) chromosome, respectively. The two fragments were joined by overlap PCR with primers 414/417. The PCR product was digested by SacI and KpnI, and then ligated between the corresponding sites of vector pRE112 to generate the plasmid pLC03, which was used to mediate the allelic exchange to generate $\Delta$ panD strain (Q1491).

The gene of $m c r-c$ was cloned from pMCR by PCR with primers 446/447, and inserted into the BamHI and HindIII sites of pBAPAT carrying PP_0596 gene from Pseudomonas putida to generate pBAPAT-MCR-C.

Random mutations were introduced into $m c r-c$ gene fragment by error-prone PCR. The reaction mixture contains $20 \mathrm{mM}$ Tris $\mathrm{HCl}$ (pH 8.4), $20 \mathrm{mM} \mathrm{KCl}, 10 \mathrm{mM}\left(\mathrm{NH}_{4}\right)_{2} \mathrm{SO}_{4}, 0.2 \mathrm{mM}$ dATP, $0.2 \mathrm{mM}$ dGTP, $1 \mathrm{mM}$ dCTP, $1 \mathrm{mM}$ dTTP, $3 \mathrm{mM} \mathrm{MgCl}$, $0.3 \mathrm{mM} \mathrm{MnCl}_{2}, 5$ units Taq polymerase, $0.1 \mathrm{mM}$ primers 446 and 447 , and pMCR-C as template. A mixture of the mutagenized $\mathrm{mcr}-\mathrm{c}$ gene was digested and ligated between the BamHI and HindIII sites of pBAPAT, and then transformed into E.coli DH5a for generation of a random mutant library.

Q1491 strain carrying $\mathrm{pA}-a c c A D B C$ was transformed with the plasmid library, and then cultivated on LB agar plates at $37^{\circ} \mathrm{C}$ overnight. The grown colonies were scraped off, rinsed with $\mathrm{ddH}_{2} \mathrm{O}$ for 3 times, diluted and spread onto the modified minimal plates $\left(14 \mathrm{~g} / \mathrm{L} \quad \mathrm{K}_{2} \mathrm{HPO}_{4} \cdot 3 \mathrm{H}_{2} \mathrm{O}, 5.2 \mathrm{~g} / \mathrm{L} \quad \mathrm{KH}_{2} \mathrm{PO}_{4}, 2 \mathrm{~g} / \mathrm{L}\left(\mathrm{NH}_{4}\right)_{2} \mathrm{SO}_{4}\right.$, $0.3 \mathrm{~g} / \mathrm{L} \mathrm{MgSO}_{4}, 1 \mathrm{~g} / \mathrm{L}$ tryptone, $10 \mathrm{~g} / \mathrm{L}$ glucose, $10 \mathrm{~g} / \mathrm{L}$ agar, $50 \mu \mathrm{M}$ IPTG, pH 7.0). After incubation at $37^{\circ} \mathrm{C}$ for $16 \mathrm{~h}$, large clones were selected and streaked on the new plates. MCR-C activity was measured using crude cell extract as described below.

\subsection{Site-directed mutagenesis and saturation mutagenesis}

Site-directed mutagenesis was performed using the QuikChange Lightning Multi-Site-Directed Mutagenesis Kit (Stratagene, USA) following the manufacturer's instruction. Saturation mutagenesis was carried out by inverse-PCR with the template pMCR-C. The PCR products were phosphorylated by 5 -polynucleotide kinase, self-ligated to generate a mixture of mutant plasmids, and then transformed into E. coli DH5a for generation of a saturation mutant library as described (Lohff and Cease, 1992).

\subsection{Protein detection, purification and enzyme assays}

The expression level of $\mathrm{His}_{6}$-tagged MCR-N and MCR-C proteins was determined by western blot analysis of crude extracts obtained by sonication of $E$. coli cells using anti-His ${ }_{6}$ antibody.

The $\mathrm{His}_{6}$-tagged MCR-C proteins were purified from $E$. coli BL21 (DE3) cell extracts with Ni-NTA HisøBind Column (Novagen) as described (Liu et al., 2013). The eluted protein was desalted by ultrafiltration, and stored in buffer containing $50 \mathrm{mM} \mathrm{NaH} \mathrm{PO}_{4}$, $300 \mathrm{mM} \mathrm{NaCl}, \mathrm{pH}$ 7.2.

The activity assay was carried out with $0.013 \mathrm{nmol}$ purified proteins as described (Liu et al., 2013). To determine the optimum $\mathrm{pH}$, the reaction condition were at $57{ }^{\circ} \mathrm{C}$ in Tris- $\mathrm{HCl}$ buffers with different $\mathrm{pH}(\mathrm{pH} 6.6,7.2,7.5,7.8,8.4$ and 9.0) or PBS buffers $\left(10 \mathrm{mM} \mathrm{NaH} \mathrm{PO}_{4}, 60 \mathrm{mM} \mathrm{NaCl}\right.$ ) with different $\mathrm{pHs}$ (pH 5.8, 6.0, 6.2, 6.6 and 7.2). To determine the optimum temperature for the mutant MCR-C, the reactions were incubated at optimum $\mathrm{pH}$ and a series of temperatures $\left(32,37,42,47,52,57,62,67,72\right.$ and $\left.77{ }^{\circ} \mathrm{C}\right)$. To determine the $K_{\mathrm{m}}$ and $K_{\text {cat }}$ values, a series of substrate malonylCoA concentrations $(0.05,0.058,0.067,0.083,0.1,0.125,0.15$ and $0.175 \mathrm{mM}$ ) were used, and reactions began under the optimum temperature and $\mathrm{pH}$ of the corresponding protein.

For mass spectrometry analysis, the enzyme reaction was stopped by addition of $1.2 \mathrm{ml}$ acetonitrile. After centrifugation, the supernatant was analyzed by high performance liquid chromatography-triple quadrupole mass spectrometer (HPLCQQQMS). Mass spectra were acquired on an Agilent 1290/6430 instrument (Agilent, CA, USA) in the negative-ion mode. Full scan mass spectra were obtained, and the ion chromatograms of malonyl-CoA, malonate semialdehyde, and 3HP were extracted using the $m / z$ of 862,87 , and 89 , respectively.

\subsection{HP production in shaking flasks}

The strains were grown overnight in LB broth and 1:100 diluted into $250 \mathrm{ml}$ Erlenmeyer flasks with $50 \mathrm{~mL}$ of minimal medium containing $14 \mathrm{~g} / \mathrm{L} \mathrm{K} \mathrm{HPO}_{4} \cdot 3 \mathrm{H}_{2} \mathrm{O}, 5.2 \mathrm{~g} / \mathrm{L} \mathrm{KH}_{2} \mathrm{PO}_{4}, 1 \mathrm{~g} / \mathrm{L} \mathrm{NaCl}, 1 \mathrm{~g} / \mathrm{L}$ $\mathrm{NH}_{4} \mathrm{Cl}, 0.5 \mathrm{~g} / \mathrm{L} \mathrm{MgSO}_{4}, 0.2 \mathrm{~g} / \mathrm{L}$ yeast extract, and $20 \mathrm{~g} / \mathrm{L}$ glucose. All shake flask experiments were carried out in triplicates. After incubation at $37^{\circ} \mathrm{C}$ for $5 \mathrm{~h}, 0.05 \mathrm{mM}$ IPTG was added for induction at $0.8 \mathrm{OD} 600$, and $3 \mathrm{~h}$ later, Biotin $(40 \mathrm{mg} / \mathrm{L})$ and $\mathrm{NaHCO}_{3}$ 


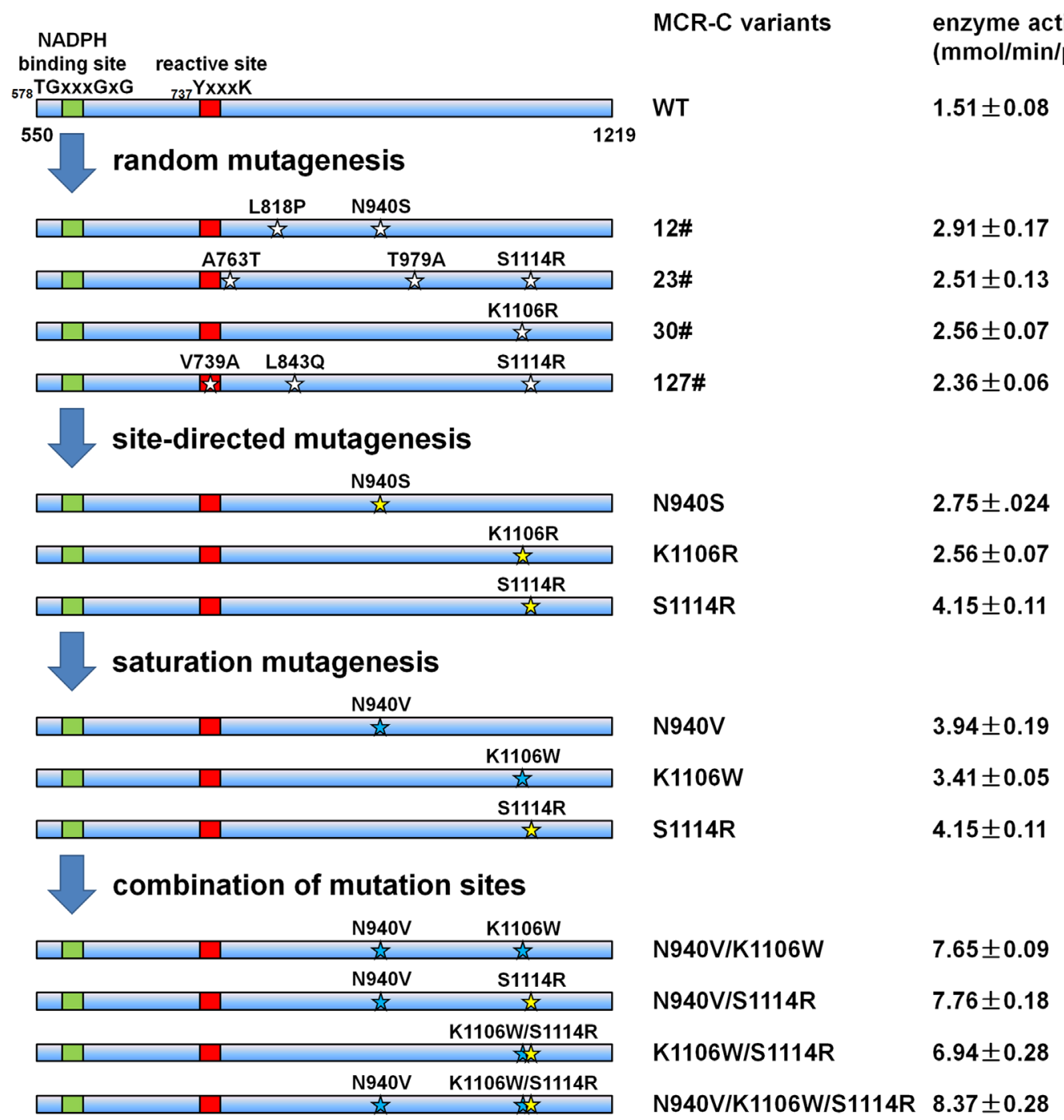

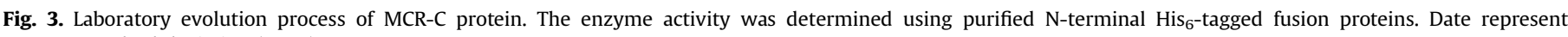
mean \pm standard deviation $(N=3)$.

(20 mM) were added. The antibiotics were supplied periodically after induction of IPTG every $12 \mathrm{~h}$ until $48 \mathrm{~h} .10 \mathrm{~g} / \mathrm{L}$ glucose was added once again after $24 \mathrm{~h}$ induction. The western blot was performed to show the expression of the target proteins in the supernatants as described (Liu et al., 2013). The crude enzyme activity was determined at $37^{\circ} \mathrm{C}, \mathrm{pH} 7.2$ with $10 \mu \mathrm{g}$ soluble protein extracts based on the similar strategy mentioned above. 3HP concentration in medium was determined by HPLC as described previously (Chen et al., 2014).

\subsection{Fed-batch fermentation}

Fed-batch cultures were carried out in a Biostat B plus MO5L fermentor (Sartorius Stedim Biotech $\mathrm{GmbH}$, Germany) containing $2 \mathrm{~L}$ of minimal medium containing $20 \mathrm{~g} / \mathrm{L}$ glucose, $9.8 \mathrm{~g} / \mathrm{L}$ $\mathrm{K}_{2} \mathrm{HPO}_{4} \cdot 3 \mathrm{H}_{2} \mathrm{O}, 3.0 \mathrm{~g} / \mathrm{L}\left(\mathrm{NH}_{4}\right)_{2} \mathrm{SO}_{4}, 2.1 \mathrm{~g} / \mathrm{L}$ citric acid monohydrate, $0.3 \mathrm{~g} / \mathrm{L}$ ammonium ferric citrate, $0.5 \mathrm{~g} / \mathrm{L} \quad \mathrm{MgSO}_{4}, \quad 9 \mathrm{mg} / \mathrm{L}$ $\mathrm{CaCl}_{2} \cdot 2 \mathrm{H}_{2} \mathrm{O}, \quad 6 \mathrm{mg} / \mathrm{L} \quad \mathrm{FeSO}_{4} \cdot 7 \mathrm{H}_{2} \mathrm{O}, \quad 2 \mathrm{mg} / \mathrm{L} \quad \mathrm{H}_{3} \mathrm{BO}_{3}, \quad 2 \mathrm{mg} / \mathrm{L}$ $\mathrm{MnCl}_{2} \cdot 4 \mathrm{H}_{2} \mathrm{O}, \quad 0.8 \mathrm{mg} / \mathrm{L} \quad\left(\mathrm{NH}_{4}\right)_{6} \mathrm{Mo}_{7} \mathrm{O}_{24} \cdot 4 \mathrm{H}_{2} \mathrm{O}$, and $0.2 \mathrm{mg} / \mathrm{L}$ $\mathrm{CuSO}_{4} \cdot 5 \mathrm{H}_{2} \mathrm{O}$. During the fermentation process, $\mathrm{pH}$ was controlled at 7.0 via automated addition of ammonia. The dissolved oxygen (DO) concentration was controlled at different levels by adjusting the agitation speed and airflow rate. After the initial carbon sources were nearly exhausted, fed-batch mode was commenced by feeding a solution containing $80 \%(\mathrm{w} / \mathrm{v})$ glucose. The expression of exogenous genes was initiated at an $\mathrm{OD}_{600}$ of 10 by adding $0.05 \mathrm{mM}$ IPTG and $40 \mathrm{mg} / \mathrm{L}$ biotin. IPTG and biotin were added every $12 \mathrm{~h}$.

\section{Results and discussion}

\subsection{Genetic selection system for active MCR-C mutants}

As a powerful vehicle for the development of proteins exhibiting desirable properties, directed evolution combines iterative cycles of gene mutagenesis, expression and sorting out the desired mutants, mimicking natural evolution (Jackel et al., 2008). In practice, isolation of rare but useful variants from complex mixtures is the most critical part of any laboratory evolution experiment. Currently, genetic selection is probably the most efficient technique available for analyzing large population of protein variants. The genetic selection system is constructed to ensure survival or growth of the host organism as a consequence of expression of an enzyme with a desired catalytic property (Taylor et al., 2001).

To enrich active variants of the MCR-C protein, a genetic selection system was developed based on the $\beta$-alanine auxotrophy. The 
Table 3

Kinetic analysis of the MCR-C mutants. ${ }^{a}$

\begin{tabular}{|c|c|c|c|c|c|}
\hline & $\mathrm{WT}^{\mathrm{b}}$ & N940V/K1106R & N940V/S1114R & K1106R/S1114R & N940V/K1106W/S1114R \\
\hline Optimal pH & 7.2 & 6.0 & 7.5 & 6.2 & 6.2 \\
\hline Optimal temp $\left({ }^{\circ} \mathrm{C}\right)$ & 57 & 62 & 72 & 62 & 72 \\
\hline$K_{\text {cat }}\left(\mathrm{s}^{-1}\right)$ & $18.6 \pm 2.4$ & $199.4 \pm 6.3$ & $209.8 \pm 3.4$ & $166.6 \pm 1.8$ & $229.2 \pm 0.1$ \\
\hline$K_{\mathrm{m}}(\mu \mathrm{M})$ & $23.8 \pm 1.9$ & $35.8 \pm 1.0$ & $21.6 \pm 0.1$ & $23.0 \pm 1.2$ & $20.7 \pm 0.8$ \\
\hline$K_{\mathrm{cat}} / K_{\mathrm{m}}\left(\mu \mathrm{M}^{-1} \mathrm{~s}^{-1}\right)$ & 0.78 & $5.6 \pm 0.1$ & $9.7 \pm 0.1$ & $7.2 \pm 0.3$ & $11.1 \pm 0.4$ \\
\hline
\end{tabular}

a The $K_{\mathrm{m}}$ and $K_{\text {cat }}$ values were determined under the optimal conditions of each enzyme.

b The data of the wild-type protein (WT) was from our previous study (Liu et al., 2013).

system relied on the E. coli BL21(DE3) $\Delta$ panD mutant, which is deficient in the biosynthesis of $\beta$-alanine (an essential precursor of CoA) and cannot grow in minimal medium. The $\beta$-alanine biosynthesis was complemented via the pathway constructed in plasmid pBAPAT-MCR-C (Fig. 2A). The characterized $\beta$-alanine-pyruvate aminotransferase (BAPAT) from $P$. putida can produce $\beta$-alanine if it is supplied with MSA as a substrate. An active MCR-C protein will produce this substrate from malonyl-CoA and enable growth on minimal media. Therefore, the activity of MCR-C protein played an essential role in the production of $\beta$-alanine, further affecting the survival and growth rate of host strains in minimal medium.

As shown in Fig. 2B, $\Delta$ panD mutant, $\Delta$ panD/pMCR-C, and $\triangle p a n D / p B A P A T$ strain were not able to grow in minimal medium, and coexpression of MCR-C and BAPAT in $\triangle$ panD strain rescued the growth to a similar level of wild-type BL21(DE3) strain, demonstrating that the system is effective to select active variants of MCR-C protein.

\subsection{Laboratory evolution of MCR-C fragment}

In order to obtain MCR-C mutants with high enzyme activity, we carried out the laboratory evolution process of this protein. A mcr-c mutant library containing approximately $10^{4}$ clones was created by random mutagenesis using error-prone PCR. The insertion rate of the library was $95.8 \%$ and the mutation rates of $m c r-c$ gene were $0.05-0.2 \%$, as estimated by DNA sequencing of 48 randomly selected clones.

After two rounds of genetic selections, 137 colonies were selected out and the MCR-C variants were purified as N-terminal $\mathrm{His}_{6}$-tagged fusion proteins for enzymatic activity determination. Four clones showed at least a 1.5 -fold increase in MCR-C activity and selected for further study. DNA sequencing revealed that one of the mutants resulted in single amino acid substitution K1106R, and the others all encoded multiple amino acid substitutions (Fig. 3).

To analyze the contribution of each mutation to the enzyme activity enhancement, site-directed mutagenesis was carried out to construct single mutants harboring each substitution identified above. Following enzymatic activity assay, three mutants (N940S, K1106R and S1114R) were identified with a positive effect on MCR$C$ enzyme activity. To further investigate the roles of the specific amino acid substitutions 940, 1106 and 1114, saturation mutagenesis was performed at each position, and two new mutations N940V and K1106W were obtained, while S1114R still remained. Different combinations of these three mutations (N940V, K1106W and S1114R) were also constructed, and all those four mutants showed at least 4.5-times higher enzymatic activity compared with wild-type MCR-C protein (Fig. 3).

\subsection{In vitro characterization of $M C R-C$ mutants}

The catalytic properties of four mutant MCR-C proteins with the highest activity (N940V/K1106W, N940V/S1114R, K1106W/ S1114R and $\mathrm{N} 940 \mathrm{~V} / \mathrm{K} 1106 \mathrm{~W} / \mathrm{S} 1114 \mathrm{R}$ ) were determined in vitro
(Table 3). The kinetic study showed that the $K_{\mathrm{m}}$ value for malonylCoA of N940V/K1106R mutant was $35.8 \pm 1.0 \mu \mathrm{mol}$, implying the lower malonyl-CoA affinity than wild-type protein, while the other mutants showed similar substrate affinity to the original MCR-C protein. $K_{\text {cat }}$ values were between $166.6 \pm 1.8$ and $229.2 \pm 0.1 \mathrm{~s}^{-1}$ for the mutants, while the highest $K_{\text {cat }}$ value being obtained for N940V/K1106W/S1114R. The overall catalytic efficiency, indicated by $K_{\text {cat }} / K_{\mathrm{m}}$, increased 7.2 - to 14.2 -fold for the mutants compared to the wild-type protein, and the highest value was obtained for the triple mutant (Table 3).

The mutation hot spots (N940, K1106, and S1114) identified above gathered at $\mathrm{C}$-terminal region of $\mathrm{MCR}-\mathrm{C}$ protein, far away from identified reactive site and NADPH binding site (Liu et al., 2013). Additionally, the MCR-C protein does not share significant sequence similarity with any known protein and its crystal structure is not published. So it is hard to understand the mechanism how those mutations lead to MCR-C activity enhancement. To solve this problem, study to elucidate MCR-C protein structure is ongoing in our lab.

\subsection{In vivo effect of $M C R-C$ mutant}

To test the in vivo effect of MCR-C mutation on 3HP production, two plasmids harboring genes encoding MCR-N, MCR-C triple mutant and acetyl-CoA carboxylase were transformed into BL21 (DE3) strain to generate strain Q2204. The strain Q2801 and its parent strain Q1319 were grown in minimal medium using glucose as the sole carbon source. After $48 \mathrm{~h}$ cultivation, the cells were collected and culture supernatant was analyzed by HPLC. The strain Q2204 accumulated $0.66 \pm 0.04 \mathrm{~g} / \mathrm{L} 3 \mathrm{HP}$, more than 4 times higher than that of strain Q1319 (Fig. 4B). This result confirmed the enhanced activity of MCR-C mutant observed in vitro.

The collected cells were disrupted by sonication, and equal amounts of soluble protein extract were used to determine the protein expression level and enzyme activity. As shown in Fig. 4C, no significant difference in protein expression could be observed in those two strains, indicating that the mutations in MCR-C fragment do not affect protein expression and solubility. The enzyme activity was tested in Tris- $\mathrm{HCl}$ buffer $\mathrm{pH} 7.2$ at $37{ }^{\circ} \mathrm{C}$ to farthest mimic $E$. coli intracellular conditions. The soluble protein extracts from strains Q1319 and Q2204 catalyzed the oxidation of NADPH at apparent activities of $0.85 \pm 0.05$ and $1.11 \pm 0.10 \mu \mathrm{mol} /$ $\mathrm{min} / \mathrm{mg}$ total protein, respectively. The kinetics of NADPH oxidation was in line with normal Michaelis-Menten kinetics (Fig. 4D), and the intermediate MSA was not detected by HPLC-MS analysis in both reaction mixtures catalyzed by soluble protein extracts from strains Q1319 and Q2204, suggesting that the initial reduction of malonyl-CoA is still rate-limiting step even though MCR-C mutant with enhanced activity was already used.

\subsection{Tuning of $M C R-N$ expression level}

To lower the expression of MCR-N, the $m c r-n$ gene was inserted into the chromosomal prpR locus through allelic exchange mediate 
A

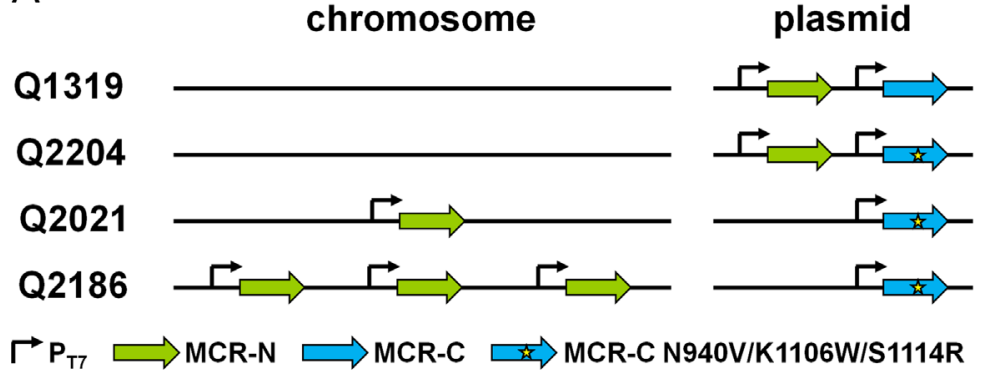

C

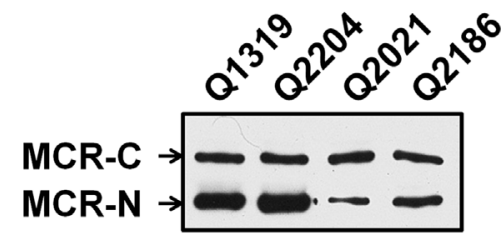

B

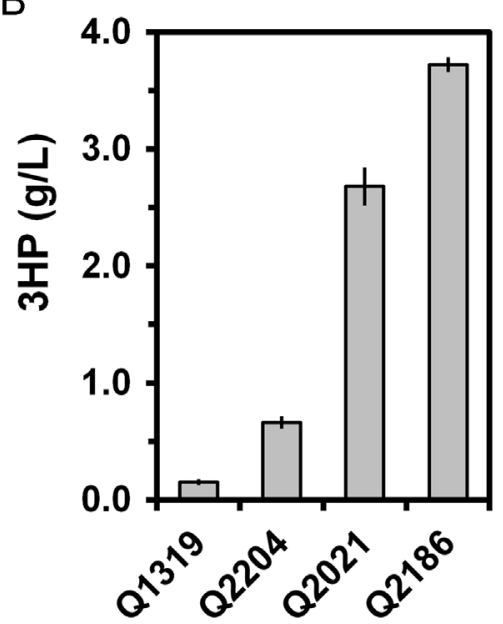

D

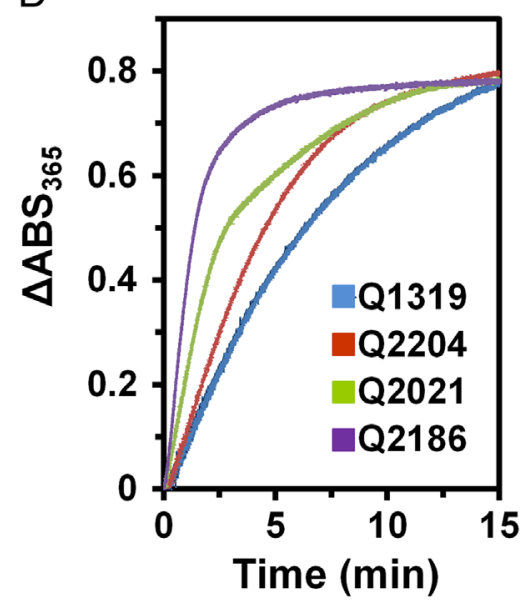

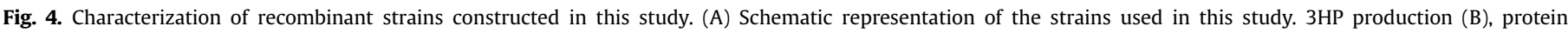

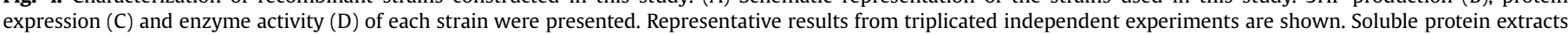

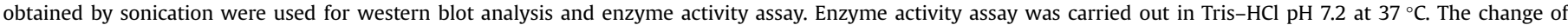
absorbance at $365 \mathrm{~nm}$ was plotted to demonstrate the oxidation rate of NADPH $\left(\varepsilon_{\mathrm{NADPH}}=3.4 \times 10^{3} \mathrm{M}^{-1} \mathrm{~cm}^{-1}\right)$.

by suicide vector pLC02. Then the 3HP producing strain Q2021 was constructed by transformation of two plasmids carrying genes encoding MCR-C triple mutant and acetyl-CoA carboxylase into the $\Delta$ prpR:mcr-n strain.

The strain Q2021 was grown in minimal medium to determine 3HP production, protein expression level and enzyme activity. As shown in Fig. 4B, the strain Q2021 produced $2.68 \pm 0.15 \mathrm{~g} / \mathrm{L} 3 \mathrm{HP}$ after $48 \mathrm{~h}$ cultivation, about 4 times higher than that of strain Q2204. Western blot result showed that the chromosomal integration of $m c r-n$ gene remarkably decreased the MCR-N expression (Fig. 4C). In an enzyme activity assay, the reaction catalyzed by Q2021 soluble protein extract presented a clear sign of two-step reaction, and NADPH was oxidized at apparent speed of $1.98 \pm 0.07$ and $0.29 \pm 0.02 \mu \mathrm{mol} / \mathrm{min} / \mathrm{mg}$ total protein in the time periods of $0-2 \mathrm{~min}$ and 3-10 $\mathrm{min}$, respectively (Fig. 4D). Furthermore, HPLC-MS analysis revealed that MSA was accumulated in the reaction mixture. All these results demonstrated that in strain Q2021, the MCR-N protein was expressed at too low a level to sufficiently reduce the MSA produced by MCR-C protein, and the transformation of MSA into 3HP became the rate-limiting step in 3HP biosynthesis.

To fulfill the functional match of MCR-N and MCR-C proteins, two more copies of $m c r-n$ gene were inserted into the chromosomal loci of melR and mtlA to generate the fourth-generation 3HP producing strain Q2186. After $48 \mathrm{~h}$ cultivation, $3.72 \pm 0.01 \mathrm{~g} / \mathrm{L} 3 \mathrm{HP}$ was synthesized by strain Q2186 (Fig. 4B). The amount of MCR-N protein was about 4-times higher than that in strain Q2021 (Fig. 4C). The reaction catalyzed by crude extract of strain Q2186 displayed normal Michaelis-Menten kinetics, NADPH was consumed at apparent speed of $3.64 \pm 0.17 \mu \mathrm{mol} / \mathrm{min} / \mathrm{mg}$ total protein during the whole reaction process (Fig. 4D) and MSA was not detectable in the reaction mixture. However, crude extract from a strain carrying two chromosomal copies of $m c r-n$ genes still converted malonyl-CoA into 3HP with features of two-step reaction. These results suggested that a functional balance between MCR-N and MCR-C proteins was achieved in strain Q2186.

\subsection{Fed-batch fermentation and process optimization}

To achieve higher 3HP production, we conducted fed-batch fermentation and optimized the fermentation conditions. The strain Q2186, which presented the highest 3HP production so far in shaking flask culture, was grown in a 5-L bioreactor. Two parameters, temperature and dissolved oxygen concentration, were controlled and monitored. Three operation temperatures, $25^{\circ} \mathrm{C}, 30^{\circ} \mathrm{C}$, and $37^{\circ} \mathrm{C}$, were tested, and $30^{\circ} \mathrm{C}$ showed a higher 3HP production. Fed-batch fermentations were then carried out under anaerobic, microaerobic (DO 1-2\% saturation), and fully aerobic ( $D O \geq 30 \%$ saturation) conditions, and the maximum $3 \mathrm{HP}$ production was achieved under fully aerobic conditions. Under optimized conditions, the strain Q2186 produced $40.6 \mathrm{~g} / \mathrm{L} 3 \mathrm{HP}$ with a yield of $0.19 \mathrm{~g} / \mathrm{g}$ glucose after $72-\mathrm{h}$ fermentation (Fig. 5). To date, this is the highest 3HP production via malonyl-CoA pathway.

The malonyl-CoA pathway with whole-length MCR protein has been reconstructed in E. coli and S. cerevisiae, and the yield of $3 \mathrm{HP}$ remained low (Chen et al., 2014; Rathnasingh et al., 2012). In our previous work, MCR was dissected into two functional fragments, and 3HP-producing strain Q1319 was constructed using separated MCR-N and MCR-C fragments. Dissection of MCR protein made it possible to figure out the enzyme activity imbalance in this pathway and tune the activity and expression of each fragment separately, resulting in significant increase of $3 \mathrm{HP}$ production. 


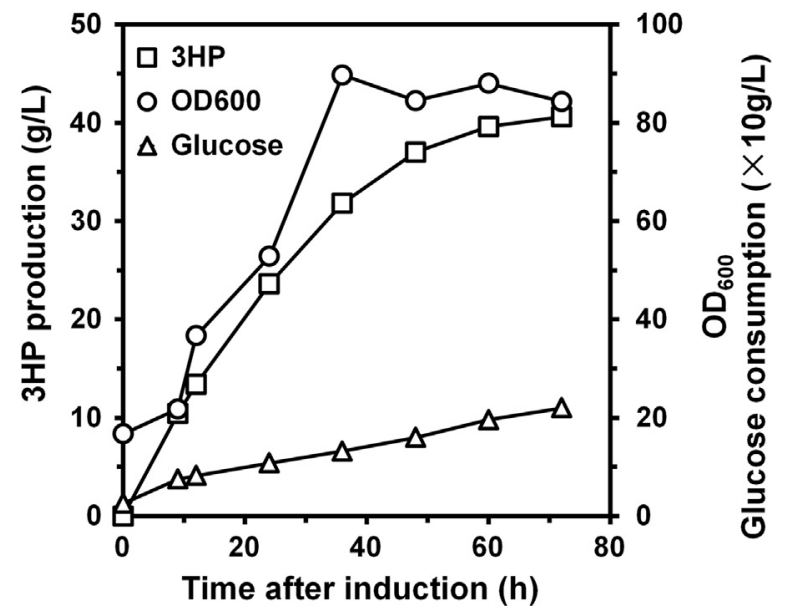

Fig. 5. Time profiles for cell growth and 3HP production during an aerobic fedbatch fermentation of strain Q2186.

These results indicated that activity of MCR is an essential factor for 3HP yield of malonyl-CoA pathway, and it is necessary to carry out further development to achieve higher activity of MCR. On the other hand, malonyl-CoA is the direct substrate to produce 3HP, and also the rate-limiting precursor for fatty acid synthesis (Liu et al., 2010). It is plausible that the availability of malonyl-CoA is limiting for the synthesis of 3HP in E. coli. Several strategies have been reported to balance the supply of malonyl-CoA for enhanced biosynthesis of various chemicals derived from malonyl-CoA, including regulating malonyl-CoA metabolism via synthetic antisense RNA (Yang et al., 2015), construction of malonyl-CoA responsive sensor (Xu et al., 2014b) and dynamically regulated pathway (Xu et al., 2014a). These strategies will greatly facilitate the high-yield production of 3HP via malonyl-CoA pathway in the future.

\section{Conclusion}

In this study, the low 3HP yield of malonyl-CoA pathway was attributed to functional imbalance between enzymes in this pathway. To improve 3HP productivity, we minimized the activity imbalance between MCR-N and MCR-C using two strategies: directed evolution of MCR-C and lowering the expression level of MCR-N. Finally, our recombinant E. coli strain accumulated $40.6 \mathrm{~g} / \mathrm{L}$ 3HP using glucose as sole carbon source under fed-batch fermentation conditions, representing the highest $3 \mathrm{HP}$ production via malonyl-CoA pathway. This study also proved the importance of metabolic balance in a multistep artificial pathway, which should be always considered in any metabolic engineering study.

\section{Acknowledgments}

This research was financially supported by the 100-Talent Project of CAS (for GZ), CAS Key Program (KGZD-EW-606-1-3), Taishan Scholars Climbing Program of Shandong (No. TSPD20150210), and Natural Science Foundation of Shandong Province (ZR2013EMZ002, ZR2015PB013).

\section{Reference}

Borodina, I., Kildegaard, K.R., Jensen, N.B., Blicher, T.H., Maury, J., Sherstyk, S. Schneider, K., Lamosa, P., Herrgard, M.J., Rosenstand, I., Oberg, F., Forster, J., Nielsen, J., 2014. Establishing a synthetic pathway for high-level production of 3-hydroxypropionic acid in Saccharomyces cerevisiae via b-alanine. Metab. Eng. 27, 57-64.

Cao, Y.J., Jiang, X.L., Zhang, R.B., Xian, M., 2011. Improved phloroglucinol production by metabolically engineered Escherichia coli. Appl. Microbiol. Biotechnol. 91, 1545-1552.

Chen, Y., Bao, J., Kim, I.K., Siewers, V., Nielsen, J., 2014. Coupled incremental precursor and co-factor supply improves 3-hydroxypropionic acid production in Saccharomyces cerevisiae. Metab. Eng. 22, 104-109.

Edwards, R.A., Keller, L.H., Schifferli, D.M., 1998. Improved allelic exchange vectors and their use to analyze 987P fimbria gene expression. Gene 207, 149-157.

Gao, Y., Liu, C., Ding, Y., Sun, C., Zhang, R., Xian, M., Zhao, G., 2014. Development of genetically stable Escherichia coli strains for poly(3-hydroxypropionate) production. PLoS One 9, e97845.

Henry, C.S., Broadbelt, L.J., Hatzimanikatis, V., 2010. Discovery and analysis of novel metabolic pathways for the biosynthesis of industrial chemicals: 3hydroxypropanoate. Biotechnol. Bioeng. 106, 462-473.

Hugler, M., Menendez, C., Schagger, H., Fuchs, G., 2002. Malonyl-coenzyme A reductase from Chloroflexus aurantiacus, a key enzyme of the 3hydroxypropionate cycle for autotrophic $\mathrm{CO}_{2}$ fixation. J. Bacteriol. 184, 2404-2410.

Jackel, C., Kast, P., Hilvert, D., 2008. Protein design by directed evolution. Annu. Rev. Biophys. 37, 153-173.

Lan, E.I., Chuang, D.S., Shen, C.R., Lee, A.M., Ro, S.Y., Liao, J.C., 2015. Metabolic engineering of cyanobacteria for photosynthetic 3-hydroxypropionic acid production from $\mathrm{CO}_{2}$ using Synechococcus elongatus PCC 7942. Metab. Eng. 31, 163-170.

Liu, C., Wang, Q., Xian, M., Ding, Y., Zhao, G., 2013. Dissection of malonyl-coenzyme A reductase of Chloroflexus aurantiacus results in enzyme activity improvement. PLoS One 8, e75554.

Liu, Q., Wu, K., Cheng, Y., Lu, L., Xiao, E., Zhang, Y., Deng, Z., Liu, T., 2015. Engineering an iterative polyketide pathway in Escherichia coli results in single-form alkene and alkane overproduction. Metab. Eng. 28, 82-90.

Liu, T., Vora, H., Khosla, C., 2010. Quantitative analysis and engineering of fatty acid biosynthesis in E. coli. Metab. Eng. 12, 378-386.

Lohff, C.J., Cease, K.B., 1992. PCR using a thermostable polymerase with $3^{\prime}$ to $5^{\prime}$ exonuclease activity generates blunt products suitable for direct cloning. Nucleic Acids Res. 20 144-144.

Raj, S.M., Rathnasingh, C., Jo, J., Park, S., 2008. Production of 3-hydroxypropionic acid from glycerol by a novel recombinant Escherichia coli BL21 strain. Process Biochem. 43, 1440-1446.

Rathnasingh, C., Raj, S.M., Lee, Y., Catherine, C., Ashok, S., Park, S., 2012. Production of 3-hydroxypropionic acid via malonyl-CoA pathway using recombinant Escherichia coli strains. J. Biotechnol. 157, 633-640.

Roland, K., Curtiss 3rd, R., Sizemore, D., 1999. Construction and evaluation of a Dcya Dcrp Salmonella typhimurium strain expressing avian pathogenic Escherichia coli 078 LPS as a vaccine to prevent airsacculitis in chickens. Avian Dis. 43, 429-441.

Taylor, S.V., Kast, P., Hilvert, D., 2001. Investigating and engineering enzymes by genetic selection. Angew. Chem. Int. Ed. 40, 3310-3335.

Wang, Q., Yang, P., xian, M., Feng, L., Wang, J., Zhao, G., 2014. Metabolic engineering of Escherichia coli for poly(3-hydroxypropionate) production from glycerol and glucose. Biotechnol. Lett. 36, 2257-2262.

Werpy, T., Petersen, G., 2004. Top value added chemicals from biomass. Office of Energy Efficiency and Renewable Energy, US Department of Energy, Washington D.C..

Xu, P., Li, L., Zhang, F., Stephanopoulos, G., Koffas, M., 2014a. Improving fatty acids production by engineering dynamic pathway regulation and metabolic control. Proc. Natl. Acad. Sci. USA 111, 11299-11304.

Xu, P., Wang, W., Li, L., Bhan, N., Zhang, F., Koffas, M.A., 2014b. Design and kinetic analysis of a hybrid promoter-regulator system for malonyl-CoA sensing in Escherichia coli. ACS Chem. Biol. 9, 451-458.

Yang, Y., Lin, Y., Li, L., Linhardt, R.J., Yan, Y., 2015. Regulating malonyl-CoA metabolism via synthetic antisense RNAs for enhanced biosynthesis of natural products. Metab. Eng. 29, 217-226.

Yu, X., Liu, T., Zhu, F., Khosla, C., 2011. In vitro reconstitution and steady-state analysis of the fatty acid synthase from. Escherichia coli. Proc. Natl. Acad. Sci. USA 108, 18643-18648. 